\title{
Activated carbon from honeydew rind as an adsorbent in zinc removal from aqueous solutions.
}

\author{
Zalilah Murni Yunus ${ }^{1, a^{*}}$,Norzila Othman ${ }^{2, b}$, Rafidah Hamdan ${ }^{3, c}$, \\ Nurun Najwa Ruslan ${ }^{4, d}$, Norfarihah Abu Kasin, Nur Solini Leman
}

\author{
${ }^{1}$ Dept. Of Sci, Fac. of Sci, Tech \& Human Development, University Tun Hussein Onn Malaysia \\ ${ }^{2}$ Dept. Of Water Eng. Fac of Civil and Env. Eng, University Tun Hussein Onn Malaysia, Malaysia \\ ${ }^{3}$ Dept. Of Civil Eng. Fac of Technol. Eng, University Tun Hussein Onn Malaysia, Malaysia \\ ${ }^{4}$ Dept. Of Sci, Fac. of Sci, Tech \& Human Development, University Tun Hussein Onn Malaysia \\ azalilah@uthm.edu.my, ${ }^{b}$ norzila@uthm.edu.my, ${ }^{c}$ rafidahh@uthm.edu.my, \\ dnurunajwa@uthm.edu.my
}

Keywords: Activated carbon, honeydew rind, wastewater treatment, zinc.

\begin{abstract}
This study focusing in producing activated carbon (AC) from honeydew rind, a low-cost agricultural by-product, by chemical activation using $\mathrm{H}_{2} \mathrm{SO}_{4}$ used as an adsorbent for the removal of zinc ions from aqueous solutions. Preparation method on the effect of surface morphology at different carbonization temperatures $450^{\circ} \mathrm{C}, 470^{\circ} \mathrm{C}, 490^{\circ} \mathrm{C}$ and $510^{\circ} \mathrm{C}$ was studied. The AC was characterized using FEM-SEM, FTIR and TG. Batch adsorptions were carried out to optimize different variables such as zinc concentration, contact time, $\mathrm{pH}$ and biosorbent amount. AAS analysis showed that the maximum adsorption of zinc onto honeydew rind $\mathrm{AC}$ was achieved at the conditions of $\mathrm{pH} 7.5,1.5 \mathrm{~g}$ biosorbent amount, $1000 \mathrm{mg} / \mathrm{L}$ initial zn concentration and $45 \mathrm{~min}$ contact time. The maximum metal uptake and maximum removal were $66.55 \mathrm{mg} / \mathrm{g}$ and $99.79 \%$ respectively.
\end{abstract}

\section{Introduction}

The persistent and non biodegradable of heavy metals had triggered in depth study on removal of heavy metals in the receiving environmental. Zinc ( $\mathrm{Zn})$ is one of heavy metals residues from various massive chemical industries such as batteries, tanneries, metal plating, agrochemicals, petrochemicals and mining $[1,2]$. Daily recommended dose of $\mathrm{Zn}$ for men, women, children and infant is $15 \mathrm{mg}, 12 \mathrm{mg}, 10 \mathrm{mg}$ and $5 \mathrm{mg}$ respectively [3]. The residue of $\mathrm{Zn}$ enters the environment mainly through water stream as untreated wastewater. People who live near waste sites containing are likely to be exposed to zinc through breathing, drinking contaminated drinking water and the polluted water. There is therefore essential to remove this metal from wastewater in order to prevent from entering natural water bodies by polluted water containing the harmful metal $[4,5]$.

At present, a list of technologies have been designed and employed for heavy metal removal purpose namely precipitation, biological treatment, membrane-filtration process, fenton reagent and adsorption [6,7]. Despite of the efficiency in pollutants removal these methods have significant disadvantages, such as high chemical and energy requirements, hazardous sludge formation, low efficiency at low concentration of pollutants and high cost at large scale [8]. Nevertheless, despite of high cost of operational, adsorption using $\mathrm{AC}$ as adsorbent is the most efficient technique and produces the least drawbacks. Hence there is a new interest among researchers on exploring alternative precursor to produce a low cost adsorbent for wastewater treatment.

Activated carbons (AC) are principally amorphous solids with large internal surface areas and pore volumes. This characteristic fit to many applications such as separation and purification technologies, catalytic processes, decolorization and wastewater treament $[9,10]$. To date, due to their adsorptive capacity, AC has been well known in the sorption of chemical species from aqueous solutions as adsorbent [11]. In spite of the fact that charcoal has been the oldest adsorbent known in wastewater treatment but the cost of operational of commercial ACs from this material is still high at US\$20/kg [12]. Therefore alternative adsorbents with economical feaseble factor; cost effective and efficiency have been the main target of recent research in this area. ACs used in 
wastewater treatment are traditionally obtained from precursors such as wood, palm kernel and animal bones [13]. However, the interest for the application of alternative and value added raw materials from crop waste has increased during last years. These non wooden materials have been utilized in many research in this area as they have potential to become an alternative biosorbent with economical feasible factors. In addition, AC derived from crop waste remains as a natural substance in ecosysytem [14-18].

This study was aimed to produce AC from non-economical honeydew rind for $\mathrm{Zn}$ removal in aqueous solutions. Prior to the chemical activation process, pre-treatment and optimization of the duration of soaking the rind in the nitric acid were studied as well as impregnation time. The surface morphology and pore surface diameter of the ACs were determined. The adsorption of $\mathrm{Zn}$ was studied with respect to the initial $\mathrm{pH}$, contact time, initial metal ion concentration and biodsorbent dose.

\section{Experimental}

\section{Raw material and preparation condition}

Honeydew rind was sorted and washed with tap water, pretreated with $5 \%$ nitric acid $\left(\mathrm{HNO}_{3}\right)$ for $4 \mathrm{~h}$, soaked in distilled water and oven dried at $60^{\circ} \mathrm{C}$. Impregnation step used $20 \%$ sulfuric acid $\left(\mathrm{H}_{2} \mathrm{SO}_{4}\right)$ for $6 \mathrm{~h}$ and oven dryied at $110^{\circ} \mathrm{C}$. Carbonization was done at $450^{\circ} \mathrm{C}, 470^{\circ} \mathrm{C}, 490^{\circ} \mathrm{C}$ or $510^{\circ} \mathrm{C}$ for $30 \mathrm{~min}$. The $\mathrm{AC}$ was washed with hot distilled water for several times followed by cold water until $\mathrm{pH}$ nuetral then dried at $110^{\circ} \mathrm{C}$. The $\mathrm{AC}$ was kept in tight container for further uses.

\section{Batch adsorption study}

Batch adsorption studies [Table 1] were carried out by orbital shaking $0.1 \mathrm{~g}$ of granular AC in $100 \mathrm{~mL}$ of aqueous solutions of $\mathrm{Zn}$ ion at $125 \mathrm{rpm}$ for $30 \mathrm{~min}$ at room temperature.

Table 1 : Experimental conditions

\begin{tabular}{|l|l|l|l|}
\hline Parameters & \multicolumn{1}{|c|}{ Range } & \multicolumn{1}{c|}{ Parameters } & \multicolumn{1}{c|}{ Range } \\
\hline $\begin{array}{l}\text { Zn initial concentration } \\
(\mathrm{mg} / \mathrm{l})\end{array}$ & $\begin{array}{l}100,500,1000, \\
1500\end{array}$ & $\mathrm{pH}$ & $6.0,6.5,7.0,7.5$ \\
\hline Contact Time $(\mathrm{min})$ & $15,30,45,60$ & Biosorbent amount $(\mathrm{g})$ & $0.1,0.5,1.0,1.5,1.8$ \\
\hline
\end{tabular}

\section{Characterization}

Surface functional groups were determined by fourier transform infrared spectra (FTIR) using SHIMADZU IR Prestige 21. Thermogravimetric (TG) analysis was performed by using a LINSEIS THERMOBALANCE with simultaneous recording of TG and differential thermogravimetric analysis (DTG) curves in relation to temperature and time. Field emission-scanning electron microscope (FE-SEM) images of AC before and after adsorption were recorded using JEOL JSM7600F Field Emission Scanning Electron Microscope (USA).

\section{Result and discussion \\ FE-SEM, TG and FTIR analysis}

The pore surface diameter of AC produced at different carbonization temperature of $20 \% \mathrm{H}_{2} \mathrm{SO}_{4}$ impregnated shown in Fig. 1 at $1000 x$ magnification. It is proposed that $\mathrm{H}_{2} \mathrm{SO}_{4}$ provokes the pyrolytic decomposition of the precursor and the arrangemnet of the crosslinked structure [17]. All diamaters were in $\mu \mathrm{m}$. At $450^{\circ} \mathrm{C}$, diameter was observed in the range of $0.201-0.306$. The undeveloped porosity on the surface changed to well-developed porosity as the temperature increased to $470^{\circ} \mathrm{C}$. The surface was observed clearer due to the decomposition removing impurities from the material [15]. Direct measurement from the micrograph showed that the average pore diameter was in the range of $0.430-0.850$. Darker area spotted compared to the images of $450^{\circ} \mathrm{C}$ may be theorize higher carbonization temperature elevate the depth of porosity development. Further observation indicated the diamaters have become larger as temperature increased to $490^{\circ} \mathrm{C}$ and $510^{\circ} \mathrm{C}$ speculated the damage of the walls' structure [16] consequently lead to pores ruptures and reduce adsorption ability. Besides, higher temperature and duration of 

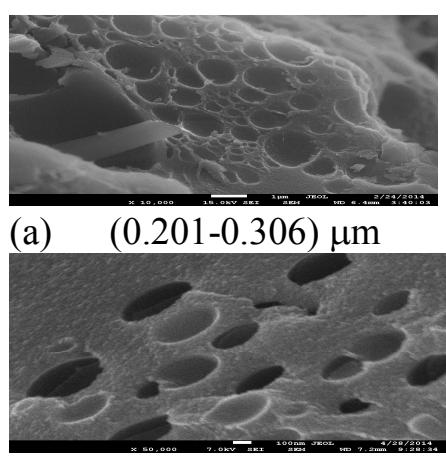

(c) $\quad(0.310-0.520) \mu \mathrm{m}$

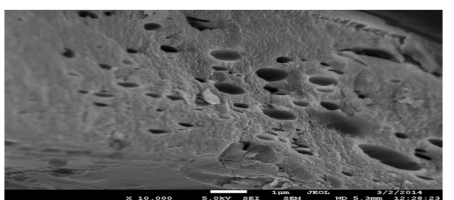

(b) $\quad(0.430-0.850) \mu \mathrm{m}$

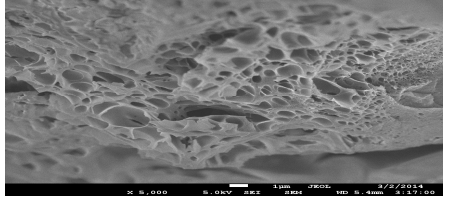

(d) $\quad(0.240-0.570) \mu \mathrm{m}$

Fig 1. The changes of surface morphology of the $\mathrm{AC}$ and their width ranges $(\mu \mathrm{m})$ at different carbonization temperature (a) $450^{\circ} \mathrm{C}$, (b) $470^{\circ} \mathrm{C}$, (c) $490^{\circ} \mathrm{C}$ and (d) $510^{\circ} \mathrm{C}$.

carbonization induced more carbon to involve hence gasification occured. As the result, ash content increases resultant more carbon to be consumed and lowered carbon yield $[13,14]$. Thus AC with pore surface diameter of (0.430-0.850) $\mu \mathrm{m}$ impregnated with $20 \% \mathrm{H}_{2} \mathrm{SO}_{4}$ and carbonized at $470^{\circ} \mathrm{C}$ was selected for batch adsorption study.

TG analysis was done to investigate thermal degradation of honeydew rind against temperature and time [Fig. 2]. The initial stage, ranging from $30^{\circ} \mathrm{C}-100^{\circ} \mathrm{C}$, involves the loss of moisture contain in the sample with approximately

of 9 wt.\%. Approximately of $7 \mathrm{wt} . \%$ loss occurred at $100^{\circ} \mathrm{C}-200^{\circ} \mathrm{C}$ related to the elemination of volatiles resulting from the decomposition of hemicellulose in the rind. The stage of $300-480^{\circ} \mathrm{C}$ was believed by the decomposition of cellulose and lignin with the maximum weight loss of $46 \mathrm{wt} \%$. This is due to breakage of chemical bonded water, bioplymer composites to carbon [16]. The weight loss was observed come to end above $475^{\circ} \mathrm{C}$ suggesting $470^{\circ} \mathrm{C}$ is suitable for preparation of the AC. The total of weight loss was $89 \%$.

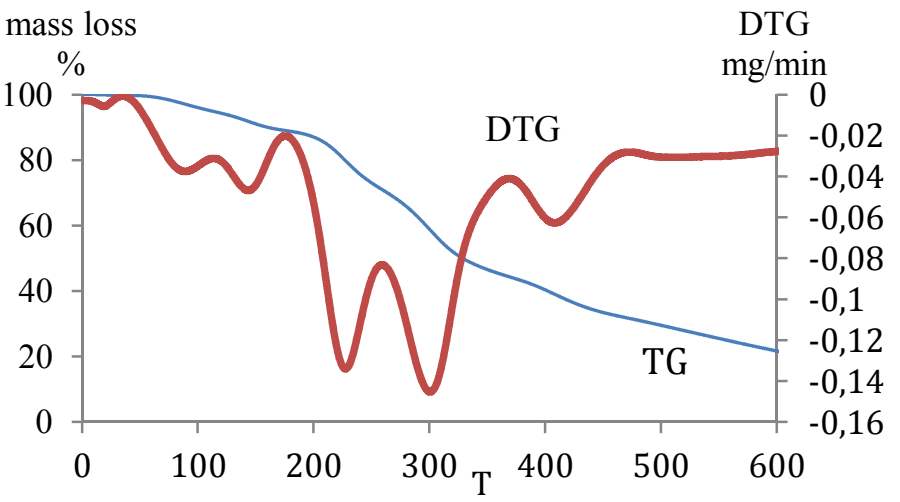

Fig. 2. TG and DTG curves of dried honeydew rind $5 \% \mathrm{HNO}_{3}$ pretreatment.

FTIR result showed [Table 2] the existance of carboxyl, hydroxyl and alcoholic functional groups. This result proved that honeydew rind AC consists same functional groups as the common plant base AC $[4,17]$. A strong and broad adsorption broad peak detected at $3307.28 \mathrm{~cm}^{-1}$ on loaded-AC (LAC) which corresponds to the stretching of $\mathrm{O}-\mathrm{H}$ and the amine $\mathrm{N}-\mathrm{H}$ groups show the existance of bonded hydroxide in the raw sample. C-O stretch appeared at $1099.21 \mathrm{~cm}^{-1}$ for unloaded-AC (ULAC) represents primary hydroxyl and secondary hydroxyl at $1110.75 \mathrm{~cm}^{-1}$ for LAC. These results indicated complexation of functional groups with $\mathrm{Zn}$ ion has changed the chemical environment of the functional groups and led to a shift of the AC functional groups in the FTIR-loaded spectra. The FE-SEM micrograph in Fig. 3(b) of LAC indicated disappearance

Table 2: Comparisons of FT-IR results from UL-AC and LAC biosorption.

\begin{tabular}{|c|c|c|c|}
\hline ULAC biosorption $\left(\mathrm{cm}^{-1}\right)$ & Identified Groups & LAC biosorption $\left(\mathrm{cm}^{-1}\right)$ & Identified Groups \\
\hline 671.10 & $\begin{array}{l}\text { Alkynes; -C } \equiv \mathrm{C}-\mathrm{H} \text { : } \mathrm{C}-\mathrm{H} \\
\text { bend }\end{array}$ & 686.52 & $\begin{array}{l}\text { Alkynes; -C } \equiv \mathrm{C}-\mathrm{H} \text { : } \mathrm{C}-\mathrm{H} \\
\text { bend }\end{array}$ \\
\hline 1099.21 & $\begin{array}{l}\text { Primary hydroxyl; } \\
\text { stretching C-O }\end{array}$ & 1110.75 & $\begin{array}{l}\text { Secondary hydroxyl, } \\
\text { stretching C-O }\end{array}$ \\
\hline 1577.46 & $\begin{array}{l}\text { Aromatic structure; } \\
\text { stretching } \mathrm{C}=\mathrm{C}\end{array}$ & 1623.75 & $\begin{array}{l}\text { Aromatic structures, } \\
\text { stretching } C=C\end{array}$ \\
\hline 2360.41 & $\begin{array}{l}\text { Alkyne triple bond, } \\
\text { nitrile triple bonds }\end{array}$ & 3307.28 & $\begin{array}{l}\text { Hydroxyl, carboxylic acid; } \\
\text { stretching O-H, N-H }\end{array}$ \\
\hline
\end{tabular}


of pores surface in Fig. 3(a). It is due to adsorbed $\mathrm{Zn}$ bound with the $\mathrm{AC}$ and most expected resultant from the process $\mathrm{Zn}$ removal from aqueous solution through biosorption process.

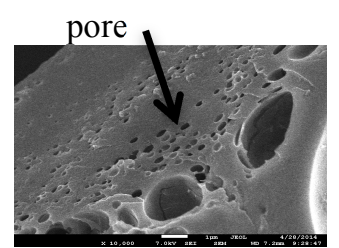

Fig. 3. Micrograph (a) ULAC and (b) LAC.

\section{Batch adsorption}

Table 3 showed maximum removal and uptake capacity for each parameters tested. In general zn removal increase for all parameters. Meanwhile $\mathrm{Zn}$ uptake capacity trend increasing and started to decrease above $7.5 \mathrm{pH}$ and $1000 \mathrm{mg} / \mathrm{L}$ zn concentration. This is due to at higher $\mathrm{pH}$ ionizatian of compounds on the sorbent surface produces negatively charged oxygen $\left(\mathrm{O}^{-}\right)$. The condition enhances the cation exchange capacity thus leads to repulsion of the positively charged $\mathrm{Zn}$ from the sorbent surface [12]. At high $\mathrm{Zn}$ ion concentrations, the ratio of surface active sites to the total metal ions in the solution was low hence not all metal ions interacted with the adsorbent and removed from the solution [13]. In contrast the uptake capacity for contact time and biosorbent amount showed a decreasing trend above 45 minutes and $1.5 \mathrm{~g}$ respectively. This could be due to higher biosorbent dose causes electrostatic interactions with the medium and interference between the bindings sites [14-15].

Table 3: Maximum $\mathrm{Zn}$ removal percentage and $\mathrm{Zn}$ uptake capacity at paramaters tested.

\begin{tabular}{|l|c|c|c|c|}
\hline \multirow{2}{*}{ Item/value } & $\mathrm{pH}$ & Initial zn concentration & Contact time & Biosorbent amount \\
\cline { 2 - 5 } & 7.5 & $1000 \mathrm{mg} / \mathrm{L}$ & $45 \mathrm{~min}$ & $1.5 \mathrm{~g}$ \\
\hline Zn removal $(\%)$ & 98.5 & 99.5 & 99.0 & 98.8 \\
\hline Zn uptake $(\mathrm{mg} / \mathrm{g})$ & 98.9 & 97.2 & 66.8 & 79.4 \\
\hline
\end{tabular}

\section{Conclusion}

ACs with developed porosity and excellent zinc adsorption performance have been prepared from the honeydew rind pretreated with $5 \% \mathrm{HNO}_{3}$, impregnated with $20 \% \mathrm{H}_{2} \mathrm{SO}_{4}$ and carbonization temperature of $470^{\circ} \mathrm{C}$. This study has convinced that the honeydew rind has fully converted to $\mathrm{AC}$ after carbonization temperature of $470^{\circ} \mathrm{C}$. The $\mathrm{AC}$ prepared from the honeydew rind has shown good adsorption capacity for zinc removal in aqueous solution. Maximum percentage removal of $\mathrm{Zn}$ is $99.78 \%$ and $\mathrm{Zn}$ uptake is $99.79 \mathrm{mg} / \mathrm{g}$ at optimized paramaters values.

\section{Acknowledgement}

The authors acknowledge the financial support provided by Ministry of Education, Malaysia under FRGS fund (Vot No 1230).

\section{References}

[1] M. M. Rao, G. P. C. Rao, K. Seshaiah, N. V Choudary, and M. C. Wang, "AC from Ceiba pentandra hulls, an agricultural waste, as an adsorbent in the removal of lead and zinc from aqueous solutions.," Waste Manag., vol. 28, no. 5, pp. 849-58, Jan. 2008.

[2] G. Issabayeva, M. K. Aroua, and N. M. Sulaiman, "Continuous adsorption of lead ions in a column packed with palm shell AC.," J. Hazard. Mater., vol. 155, no. 1-2, pp. 109-13, Jun 2008.

[3] ATSDR Registry, "Toxicological profile for Zinc," US Department of Health and Human Services, 2005.

[4] V. K. Gupta, "Chapter 2 - Water Treatment for Inorganic Pollutants by Adsorption Technology," Environ. WaterAdvances Treat. Remediat. Recycl., pp. 29-91, 2013.

[5] H.-C. Hsi, R. S. Horng, T.-A. Pan, and S.-K. Lee, "Preparation of ACs from Raw and Biotreated Agricultural Residues for Removal of Volatile Organic Compounds," J. Air Waste Manage. Assoc., vol. 61, no. 5, pp. 543-551, May 2011. 
[6] I. Nhapi, N. Banadda, R. Murenzi, C. B. Sekomo, and U. G. Wali, "Removal of Heavy Metals from Industrial Wastewater Using Rice Husks," Open Environ. Eng. J., vol. 4, pp. 170-180, 2011.

[7] X. Ren, C. Chen, M. Nagatsu, and X. Wang, "Carbon nanotubes as adsorbents in environmental pollution management: A review," Chem. Eng. J., vol. 170, no. 2-3, pp. 395410, Jun. 2011.

[8] A. K. Minocha, "Conventional and non-conventional adsorbents for removal of pollutants from water - A review," vol. 13, no. May, pp. 203-217, 2006.

[9] Puziy, A. M. and Poddubnaya, O. I., Martinez-Aonsi, A., Suarez-Gracia, F., Tascon, J. M. D., "S ynthetic carbons activated with phosphoric acid I . Surface chemistry and ion binding properties," vol. 40, pp. 1493-1505, 2002.

[10] Abdolali, H. H. Ngo, W. S. Guo, D. J. Lee, K. L. Tung, and X. C. Wang, "Development and evaluation of a new multi-metal binding biosorbent.," Bioresour. Technol., Dec. 2013.

[11] M. Bilal, J. A. Shah, T. Ashfaq, S. M. H. Gardazi, A. A. Tahir, A. Pervez, H. Haroon, and Q. Mahmood, "Waste biomass adsorbents for copper removal from industrial wastewater-A review.," J. Hazard. Mater., Aug. 2013.

[12] S. M. B Amit, "Utilization of agro-industrial and municipal waste materials as potential adsorbents for water treatment-A review," Chem. Eng. J., vol. 157, no. 2-3, pp. 277-296, 2010.

[13] J. M. González-domínguez, C. Fernández-gonzález, M. Alexandre-franco, A. Ansón-casaos, and V. Gómez-serrano, "The influence of the impregnation method on yield of AC produced by H 3 PO 4 activation," Mater. Lett., vol. 65, no. 9, pp. 1423-1426, 2011.

[14] B. Corcho-Corral, M. Olivares-Marín, C. Fernández-González, V. Gómez-Serrano, and a. Macías-García, "Preparation and textural characterisation of AC from vine shoots (Vitis vinifera) by $\mathrm{H}_{3} \mathrm{PO}_{4}$ - Chemical activation," Appl. Surf. Sci., vol. 252, no. 17, pp. 5961-5966, Jun. 2006.

[15] R. M. Suzuki, a D. Andrade, J. C. Sousa, and M. C. Rollemberg, "Preparation and characterization of AC from rice bran.," Bioresour. Technol., vol. 98, no. 10, pp. 1985-91, Jul. 2007.

[16] J. Krook, A. Mårtensson, and M. Eklund, "Sources of heavy metal contamination in Swedish wood waste used for combustion.," Waste Manag., vol. 26, no. 2, pp. 158-166, 2006.

[17] M. Sadiq and S. Hussian, "An Efficient AC for the Wastewater Treatment, Prepared from Peanut Shell,” vol. 2013, no. October, pp. 148-156, 2013. 